This item was submitted to Loughborough's Research Repository by the author.

Items in Figshare are protected by copyright, with all rights reserved, unless otherwise indicated.

\title{
Unlocking the potential of the internet of things to improve resource efficiency in food supply chains
}

PLEASE CITE THE PUBLISHED VERSION

https://doi.org/10.1007/978-3-030-02312-6

\section{PUBLISHER}

Springer International Publishing @ Springer Nature Switzerland AG

\section{VERSION}

AM (Accepted Manuscript)

\section{PUBLISHER STATEMENT}

The final authenticated version is available online at https://doi.org/10.1007/978-3-030-02312-6.

\section{LICENCE}

CC BY-NC-ND 4.0

\section{REPOSITORY RECORD}

Jagtap, Sandeep, and Shahin Rahimifard. 2019. "Unlocking the Potential of the Internet of Things to Improve Resource Efficiency in Food Supply Chains”. figshare. https://hdl.handle.net/2134/35119. 


\title{
Unlocking the Potential of the Internet of Things to Improve Resource Efficiency in Food Supply Chains
}

\author{
Sandeep Jagtap and Shahin Rahimifard \\ Centre for Sustainable Manufacturing \& Recycling Technologies (SMART), Loughborough University, Loughborough \\ LE11 3TU, United Kingdom, e-mail: S.Jagtap@lboro.ac.uk and S.Rahimifard@lboro.ac.uk
}

\begin{abstract}
The food sector is under tremendous pressure to make its supply chains more resource efficient. In this context, the focus is on the reduction of the three nexus components which are food waste, energy and water. One of the key challenges identified in improving resource efficiency is the low availability of real-time data to all the actors of the food supply chain (FSC) which inhibits better decision-making capability. Having such an ability would increase the productivity of the supply chain. The Internet of Things (IoT) concept, which has been around for a few years now, provides the possibility of monitoring, bringing in transparency and efficiency to supply chain activities. This paper investigates the practicability of utilising IoT concepts to improve the resource efficiency of FSCs. An IoT-based framework and methodology are proposed to integrate suitable data into supply chain decision-making processes for the reduction of nexus components.
\end{abstract}

Keywords: Internet of Things, IoT, Food Supply Chain, Resource Efficiency, Energy, Water, Food Waste.

\section{Introduction}

The Food Supply Chain (FSC) frequently face the concerns such as resource scarcity, food wastage, non-consistent productivity and from time to time a lack of resilience (Parfitt et al., 2010). Consumer demand for fresh, high quality and low-priced food products (Rahimifard et 
al., 2017) has increased the intricacies of global Food Supply Chains (FSCs). On top of that, changes in consumption patterns and growing population, which is estimated to cross 9 billion by 2050, are adding pressure to the already strained supply chain (European Commission, 2011). These issues are forcing FSCs to be more resource efficient.

One of the ways to overcome the resource constraint issue is by making the efficient use of resources and reducing the adverse environmental impact. Sustainable food production and consumption need consideration of all the stages of food production up until consumption. It is necessary to focus on sustainable lifestyles, sustainable diets, food losses and food waste management and recycling, sustainability standards and environmentally friendly actions and techniques to reduce resource consumption and adverse environmental impacts (FAO, n.d.). Sustainable FSCs attempt to achieve high standards of environmental performance by reducing energy consumption and minimising resource inputs (DEFRA, 2002). Some researchers have deduced that FSCs suffer due to unawareness of resource consumption, and food losses and wastage could be avoided by using novel monitoring technologies (Jedermann et al., 2014). There are other benefits of implementing monitoring technologies such as financial savings, adhering to environmental regulations set by governments and fulfilling consumer demand for sustainable food products through sustainable production and consumption (Haight \& Park, 2015).

Access to real-time resource consumption data offers a new prospect of making the FSC more resource efficient. The Internet of Things (IoT), which is a network of interconnected elements embedded with sensors, network connectivity, software and other electronics, has the capability of collecting real-time resource consumption data on behaviours and patterns. It can monitor, communicate and interact with various things almost $24 / 7$ in real-time. Currently, within the FSC, IoT applications play a crucial role in food safety and traceability solutions (Wang \& Zhang, 2014). They have been deployed to some extent in reducing food 
loss and waste (Jedermann et al., 2014), water (Kim et al., 2008) and energy (Haller et al., 2008) consumption (Combaneyre, 2015).

This paper considers the benefits of adopting IoT to support and improve the resource efficiency of FSCs. It proposes an IoT-based framework and methodology for incorporating resource consumption data in the FSC decisions. The framework and methodology are expected to facilitate an improvement in supply chain practices by minimising water and energy use as well as a reduction in food wastage. Due to the significant range and type of activities of FSC actors, the scope of work reported in this paper is restricted to post-farmgate to retailer's shelf as depicted in Figure 1 (highlighted in yellow).

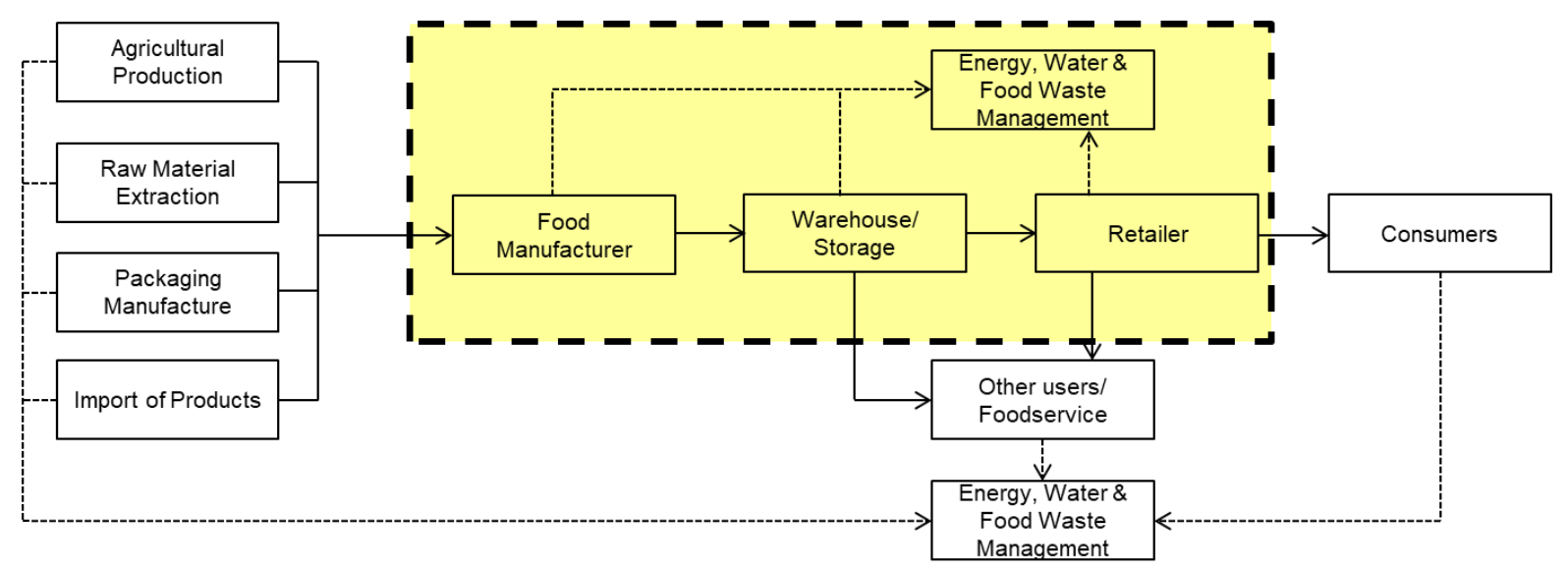

Figure 1 Research Scope (Jagtap \& Rahimifard, 2017)

\section{Review of Resource Efficiency in FSCs}

Prevailing FSC systems and methods are not sustainable in the face of continuously growing demand for important resources such as food ingredients, energy and water. Therefore, researchers and FSC practitioners are trying to develop a resource efficient, sustainable FSC without harming overall supply chain productivity (Koh, 2014). Managing resource consumption in FSCs can be a tough task because of the complexity involved arising from how the resources are consumed across various processes, with each process having individual resource consumption characteristics. Hence, at Nestle (like many other larger 
companies) an integrated and holistic approach is taken towards resource efficiency by considering energy, greenhouse gas emissions, water and materials (Brabeck-Letmathe, 2016). There are significant opportunities for desirable, sustainable production through the improvement of communication between producers, retailers, and consumers (Henningsson et al., 2004). But the absence of reliable and easily accessible data is reported as one of the major obstacles in achieving a high level of resource efficiency in FSCs (Lee et al., 2013). Another issue is that food actors are not fully aware of their resource consumption. For example, they are well informed of total water consumed and water released in the form of effluent, but usually oblivious of water consumed by the individual machine or process level (Webb, 2016) which is also relevant to energy consumption (Thollander \& Ottosson, 2010).

A better understanding of nexus components can lead to a reduction in consumption as they are interlinked in such a way that changes to one component can impact one or both the components (Villamayor-Tomas et al., 2015). But, then it is necessary to have access to meaningful, accurate and real-time data in order to reduce waste and inefficiencies in the FSC (Shahrokni et al., 2014) with regards to energy and water consumption and food waste produced by supply chain practices. Therefore, to make supply chains resource efficient, the first step is to be resource aware (Matopoulos et al., 2015) and for that real-time data is crucial as it optimises resource efficiency (Pitarch et al., 2017). The conventional methods of obtaining data using pen and paper are non-productive, slow and arduous. Hence, IoT-based applications can address those issues successfully as they can make the whole process transparent, fast and reliable. For example, IoT-based smart water meters are vital to water users as they can present real-time data on water usage, leakages and quality, and in some circumstances, could make water-efficient decisions by understanding their surrounding environment (Iotsens, 2017). 


\section{Internet of Things (IoT) based FSCs}

The rise of the IoT is rapidly changing and affecting all areas of businesses by increasing the benefits for all actors within the supply chain. It has been successfully adopted in the logistics, manufacturing, retailing and healthcare sectors. The IoT offers a platform for the network of sensors and actuators that can exchange information and communicate conveniently through an integrated framework. It can execute various functions such as ubiquitous sensing, data analytics, and cloud computing to develop a seamless operation for enabling state-of-the-art applications (Gubbi et al., 2013). It offers the opportunity to continuously gather information and send it to cloud-based software tools to store, visualise and analyse data in real-time and enables better decision-making. The IoT usually relies on Radio Frequency Identification (RFID) and Wireless Sensor Networks (WSN) technology to collect real-time data from various hotspots within the supply chain (Verdouw et al., 2016). It allows provision for continuous and massive data collection about machine availability, stock levels, traceability of products and resource consumption through multiple sensors and smart meters. RFID tags are widely used in logistics, pharmaceuticals, retailing, and supply chain management for identifying, tracking and monitoring products and things (Amendola et al., 2014). WSN technology uses interconnected intelligent sensors to sense and track and finds wider applications in the area of environmental conditions, health-care and industrial monitoring (Akkas, 2016). Table 1 shows a list of companies adopting IoT technologies to improve resource efficiency in FSCs. 


\begin{tabular}{|c|c|c|c|c|}
\hline Companies & $\begin{array}{l}\text { Resource } \\
\text { Monitoring }\end{array}$ & $\begin{array}{l}\text { Parameters } \\
\text { being } \\
\text { checked for }\end{array}$ & $\begin{array}{l}\text { Benefits of IoT } \\
\text { adoption (resource } \\
\text { efficiency -related) }\end{array}$ & $\begin{array}{l}\text { Practices enabled by } \\
\text { IoT which lead to } \\
\text { those benefits }\end{array}$ \\
\hline Rova & Energy & $\begin{array}{l}\text { Operation } \\
\text { efficiency }\end{array}$ & $\begin{array}{l}\text { Optimising truck } \\
\text { routes and bin } \\
\text { collection times }\end{array}$ & $\begin{array}{l}\text { Provides vehicle } \\
\text { location, traffic } \\
\text { congestion and bin } \\
\text { volumes }\end{array}$ \\
\hline Siemens & Energy & $\begin{array}{l}\text { Production } \\
\text { and } \\
\text { maintenance } \\
\text { effectiveness }\end{array}$ & $\begin{array}{l}\text { Increasing } \\
\text { productivity }\end{array}$ & $\begin{array}{l}\text { Provide alerts and } \\
\text { schedules about } \\
\text { machine maintenance } \\
\text { to avoid future } \\
\text { breakdowns. }\end{array}$ \\
\hline Martec & Water & $\begin{array}{l}\text { Cleaning } \\
\text { process }\end{array}$ & $\begin{array}{l}\text { Maintaining } \\
\text { hygiene standards }\end{array}$ & $\begin{array}{l}\text { Avoids over-cleaning } \\
\text { and microbial } \\
\text { contamination }\end{array}$ \\
\hline 2 Sisters & Water & $\begin{array}{l}\text { Washing } \\
\text { raw material }\end{array}$ & $\begin{array}{l}\text { Water consumption, } \\
\text { reduction in the } \\
\text { effluent }\end{array}$ & $\begin{array}{l}\text { Control system to } \\
\text { deliver exact quantity } \\
\text { needed }\end{array}$ \\
\hline MyFresh & Water & $\begin{array}{l}\text { Washing } \\
\text { raw produce }\end{array}$ & $\begin{array}{l}\text { Water consumption, } \\
\text { Reduced effluents }\end{array}$ & $\begin{array}{l}\text { Reduced incoming } \\
\text { water pressure, } \\
\text { Installation of efficient } \\
\text { pumps }\end{array}$ \\
\hline LeanPath & Food & Food waste & $\begin{array}{l}\text { Reduction in food } \\
\text { waste }\end{array}$ & $\begin{array}{l}\text { Reasons for food waste, } \\
\text { changing the } \\
\text { production process }\end{array}$ \\
\hline $\begin{array}{l}\text { Winnow } \\
\text { Solutions }\end{array}$ & Food & Food waste & $\begin{array}{l}\text { Reduction in food } \\
\text { waste }\end{array}$ & $\begin{array}{l}\text { Reasons for food waste, } \\
\text { recipe change, } \\
\text { production planning }\end{array}$ \\
\hline
\end{tabular}

Table 1 IoT adoption by companies and its benefits (Jagtap \& Rahimifard, 2017)

The application of the IoT concept for monitoring and tracking of resources in FSCs is at a relatively early stage when compared to the other manufacturing sectors (Verdouw et al., 2016). Few actors within FSCs from food producers to food retailers have adopted IoT to optimise a section or the entire process as shown in Figure 2. Some of the pioneers have even implemented it for monitoring energy and water consumption and food waste management at equipment level as illustrated in Table 1.

The application of the IoT in FSCs has resulted in some benefits, namely three areas which have been recognised as follows: 


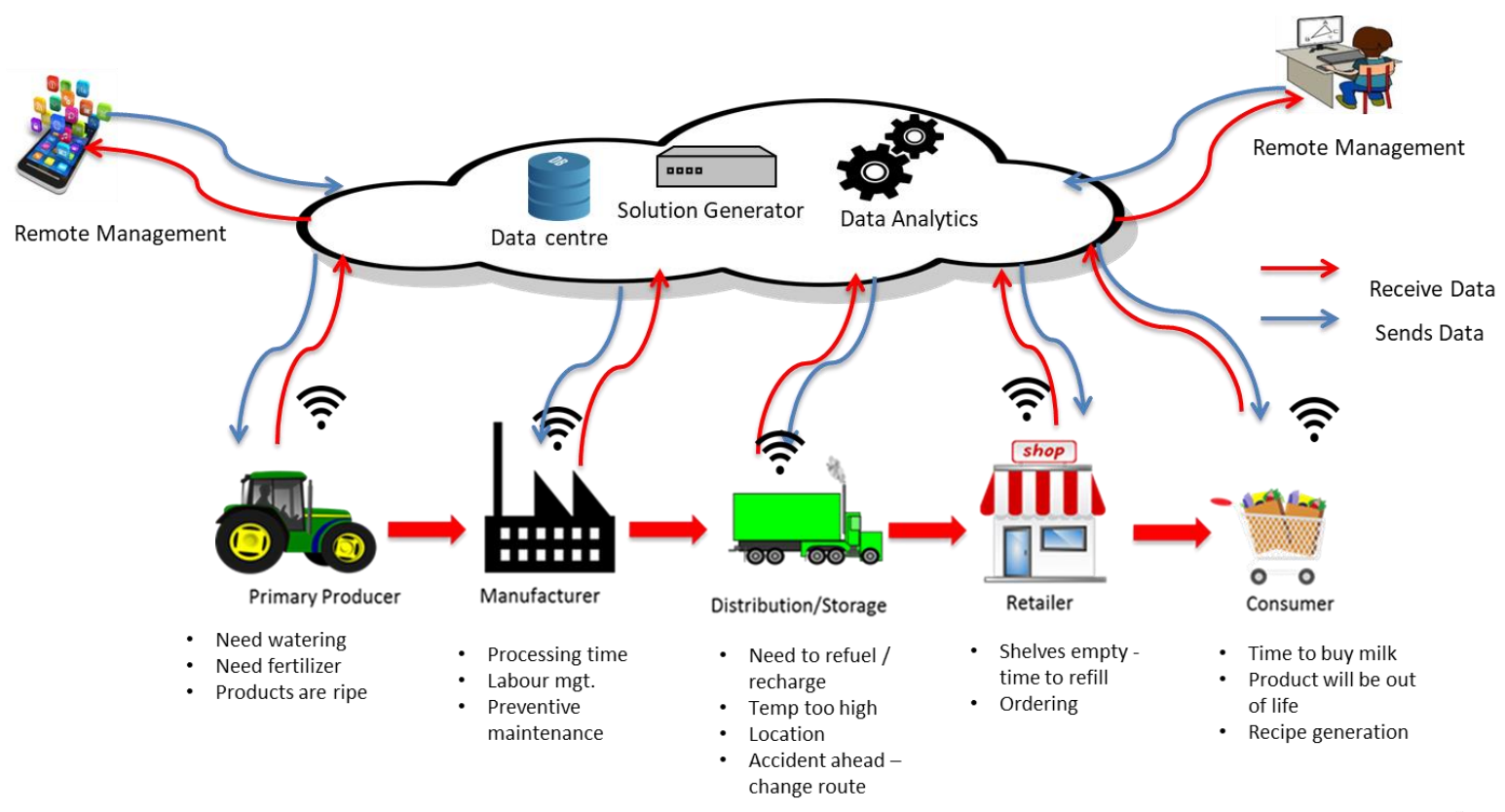

Figure 2 IoT applications in FSC

1. Operational efficiency - Some of the food companies have recognised the benefits of investing in IoT and Big Data solutions. Utilising data analytics can help to ensure sustainable and profitable growth for the entire FSC. Data analytics provides insight into machine performance, predictive maintenance requirements and real-time inventory tracking (Satyavolu et al., 2014). It can help to identify inefficiencies, low productivity on the production shop floor and suggest real-time actionable solutions. For example, it supports the continuous improvement of FSCs' operational activities through decentralisation of the decision-making process by the generation of resourceoriented key performance indicators. Availability of 24/7 resource consumption patterns in real-time enables stakeholders to plan and prioritise the efficient use of resources (Pang et al., 2012).

2. Food safety - In 2017, a chicken safety scandal at a 2 Sisters factory in the UK prompted the need to focus on compliance, prevention and a proactive approach when it comes to food safety. Strengthening of food safety and food traceability throughout the FSC, i.e. from farm to fork, is necessary to reduce foodborne-related illnesses. The 
use of real-time tracking can support monitoring of food safety data points to enable compliance with local and global regulations. By implementing IoT-based automated Hazard Analysis and Critical Control Point (HACCP) specifications during various food operation activities, supply chain actors have access to consistent, reliable, meaningful data that allow them to devise food safety solutions.

3. Transparency - The horsemeat scandal of 2013 severely damaged the consumer confidence in processed foods, and they now expect more openness from supply chain actors. By implementing full transparency and visibility along the complex global supply chain will aid the food sector to drive consumer trust back into food products. Combining Blockchain with IoT technologies can secure the data so that it makes tough for anyone to forge the records (Jesus et al., 2018). Thus, bringing transparency to support FSC actors with added benefits such as greater trust, cost savings, better inventory management and better lead times.

\section{IoT Architecture for Resource Efficiency in FSCs}

The application of the IoT for resource efficiency consists of four layers: the sensing layer, the network layer, the service layer, and the application layer (Ray, 2016) as shown in Fig 3. These layers form the IoT architecture and are designed in such a way that the system can meet the requirements of FSCs to minimise energy and water consumption and reduce food waste.

The functions of the four layers are described as follows:

- Sensing layer - In this layer data is collected for energy, water and food waste using various sensing technologies such as load cells, smart-meters, sensors, cameras, and RFID tags (Akyildiz et al., 2002; Li \& Xu, 2017). For measuring energy and water consumption, corresponding smart-meters are needed (Hancke et al., 2012) while 
solid food waste can be measured using load cells and image processing technology and liquid food waste with the respective smart-meter.

- Network layer - In this layer the collected data from the sensing layer is made available to the service layer for further analysis and storage, using a variety of modern technologies such as $\mathrm{WiFi}$, Bluetooth, and other electronics devices or hardware (Arduino, Raspberry Pi, etc.) (Sethi \& Sarangi, 2017).

- Service layer - In this layer, the collected data is stored in the cloud or on a local server (Akyildiz et al., 2002). The collected data is analysed using data analytics platforms to extract meaningful information ( $\mathrm{Li} \& \mathrm{Xu}, 2017)$.

- Application layer - This layer provides user-friendly applications or services to stakeholders or users (Sethi \& Sarangi, 2017) with accurate data to manage projects on minimising resource consumption or waste.

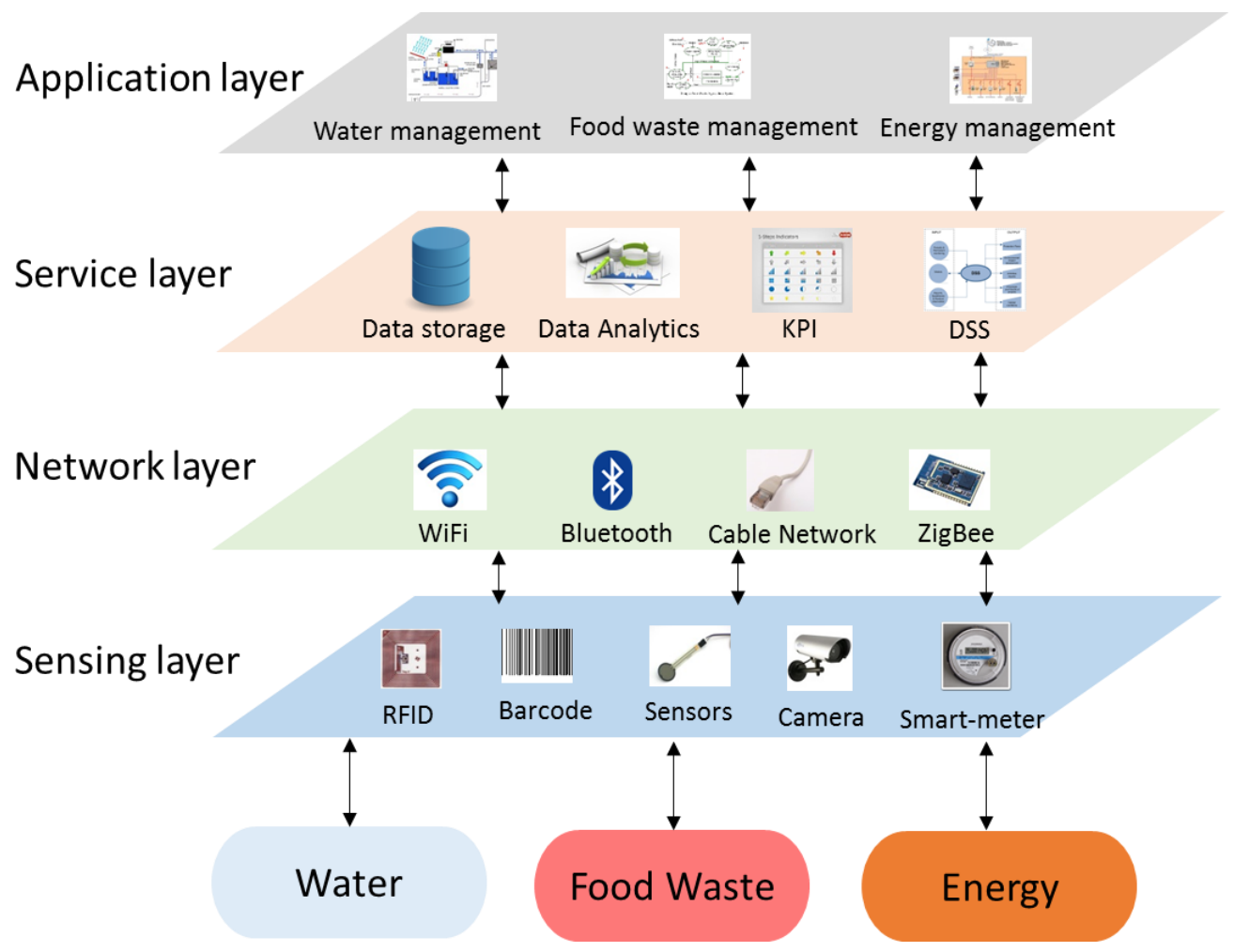

Figure 3 IoT Architecture for Resource Efficiency in FSCs (Jagtap \& Rahimifard, 2017) 


\section{IoT-based Framework for Resource Efficiency in FSCs}

Our literature review highlighted the urgent need for an IoT-based framework to be implemented in FSCs. Therefore, a four-stage IoT-based framework for resource efficiency in FSCs is developed and presented in Figure 4. The four stages are described as follows:

1. Establishing impactful resources - In this stage, it is important to determine impactful resources. The literature review focused on three key nexus components to be addressed: food waste, energy and water. The other necessary criteria are to assess and interpret the resource-use impact on the environmental sustainability of FSCs and the strategies implemented by various actors in FSCs conecrning resources.

2. Supply chain process - In this stage, it is essential to realise how resources flow within various actors of the supply chain. For example, if we consider resource flow at the factory level, it will be vital to learn the resource flow within different departments of the company, which may be further narrowed down to the machine level. These would help in interpreting the consumption behaviours and wastage of resources at various levels.

3. IoT Modelling - The third stage will be to build an IoT model. In this stage, it is essential to identify what kinds of hardware, sensors, electronics, software or technology are needed to collect resource consumption or wastage data. Also, it is necessary to know from where within the supply chain network the data can be extracted and how this data will be filtered to get meaningful information to support supply chain decisions concerning resource efficiency.

4. Generate recommendation or solution - In this stage, the valuable information generated through the IoT concepts will be used to produce reports for better planning of resources in FSCs and the improvement of supply chain activities.

\section{Methodology for IoT- based incorporation of data into FSC decisions}


By integrating the four stages of the framework as shown in Figure 4 into the FSC, resource efficiency can be improved. The real-time data produced using IoT concepts with the aid of smart-meters, sensors and cameras will be used to increase the resource awareness of each FSC activity and will create a set of new standards. It will enable energy and water consumption and food waste to be considered during planning activities leading to the optimisation of resources, flexibility in production planning and control, better communication and decision making at all actor levels. The three nexus components can be minimised through stepwise implementation of the IoT framework. Establishing what information needs to be collected regarding these resources is described below.

1. Water - Water used in food manufacturing can be categorised as production water and non-production water.

- Production water -The water used directly by food production processes. Production water is further divided into two categories, process water and system water.

Process water - The water required to convert raw ingredients into finished food products (e.g. washing fruits and vegetables, boiling, cooking)

System water -The water used to run production machines, tools, and environment (e.g. cleaning of equipment, heat exchangers).

- Non-production water - The water used by facilities or infrastructures to support production activities such as heating and sanitation (Sachidananda, 2016).

Therefore, separate meters are required to record accurate data on water consumption. 


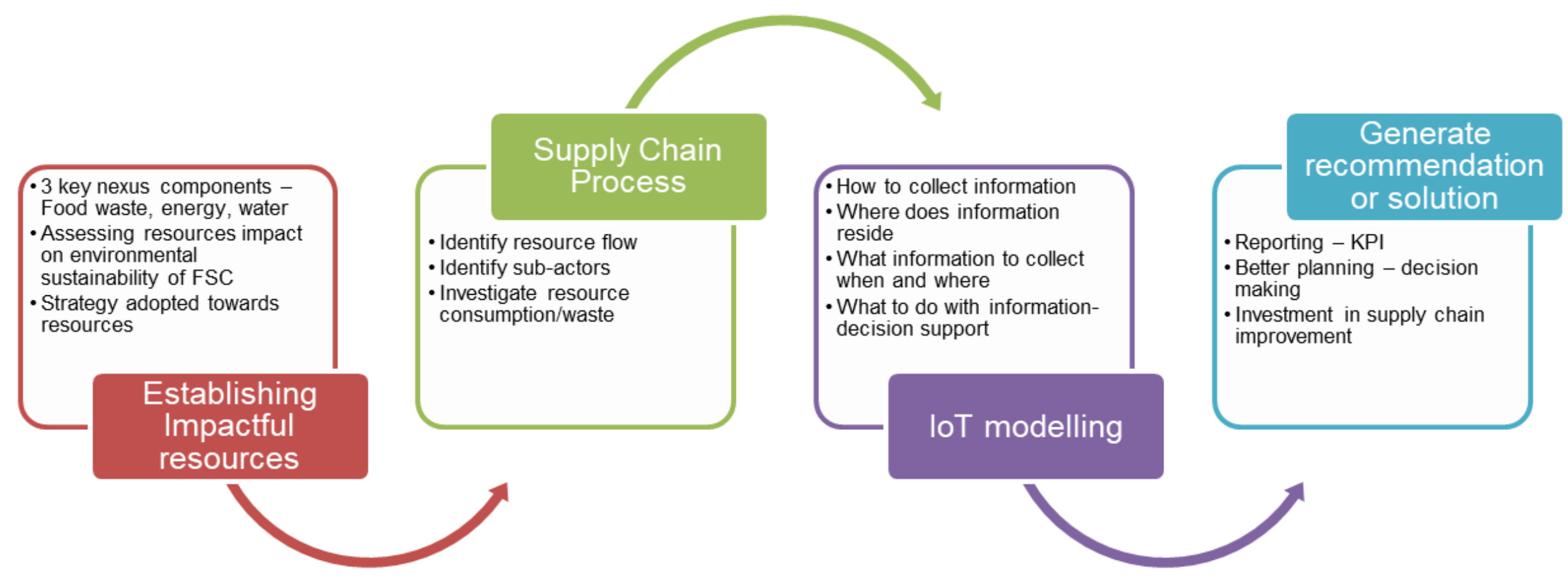

Figure 4 IoT Framework for resource efficiency in FSCs 
2. Energy - Energy can be distinguished in two ways: direct and indirect energy.

- Direct energy -The energy required by various processes within FSCs to make a finished food product available at the retailer's shelf (e.g. cleaning, washing, chopping, packing, chilling, transporting).

- Indirect energy - The energy utilised by surroundings in which food production processes are carried out, or food is stored and transported (e.g. lighting, ventilation, heating) (Seow, 2011). It is crucial for the supply chain actors to install energy smart-meters to track both types of energies in order to get a better understanding of energy consumption.

3. Food Waste - Food waste is of three kinds: avoidable, unavoidable and possibly unavoidable waste.

- Avoidable waste - Food and drink that is binned and which at some stage before its disposal was edible (e.g. bread loaves, meat, cheese, etc.).

- Unavoidable waste - Waste generated from food and drink production that is non-edible under normal circumstances (e.g. bones, banana skins, egg shells, etc.).

- Possibly avoidable waste - Food and drink that some people may consume, and others cannot (e.g. bread crumbs, potato skins, etc.). (WRAP, 2009)

Measuring solid food waste is a complex process since it is a mixture of avoidable, unavoidable or possibly avoidable waste. Therefore, to overcome this issue, food waste smart-meters to monitor and measure different types of solid food wastes with minimal human input can be deployed at various hotspots within FSC.

The data on the three nexus components collected by smart meters in real-time is stored in the cloud or on a server and analysed to extract useful information as shown in Figure 5. Data analytics techniques can be utilised to understand the consumption pattern and wastage 
behaviour of the three nexus components. In the next stage, the meaningful information created can be merged into FSC management systems and tools that support improvement in resource efficiencies, such as decision support systems (DSSs), key performance indicators (KPI) and real-time consumption dashboards. The useful information obtained from the data analytics would support high-level choices with regards to the strategic, operational and control decisions in the FSC's management systems.

In future, the ability of IoT applications to provide on-time data will play a decisive role in creating production plans, updating production line status, tracking the current status of resource consumption, the wastage during each activity and monitoring production activities throughout the FSCs. The IoT can be integrated into IT planning systems to visualise realtime data on stock levels, stock movements, machine and labour availability, etc. enabling stakeholders to make better decisions (Satyavolu et al., 2014).

\subsection{Data Storage and Analysis}

To be resource aware with regards to resource consumption and waste, it is important to select the right sensors and smart meters and to install them at the right locations (e.g. production area or section, machine). The information collected via sensors and smart meters is stored and analysed at the actor level or stored in the cloud. The results through analysis of data are sent to the actors continuously in the real-time or if there is an abnormal consumption or waste of resources. In short, data is summarised online, stored, and audited for online or offline analysis.

\subsection{Incorporating data into IT infrastructure}

Resource consumption, as well as food waste data, should be incorporated into planning systems, to allow better decisions with regards to production planning, scheduling, storing, ordering and other resource management practices. Although the communication between 
sensors or smart meters and existing planning systems could be complicated, sensors can return results in different file formats such as XML, JSON and CSV files (Solaredge, 2016). The planning system providers (Enterprise Resource Planning (ERP) vendors) such as Epicor (Solarsoft), SAP, Sage X3 are upgrading their existing planning systems to accommodate resource management know-how (Compare Business Products, n.d.). These solutions allow resources as well as waste data monitoring, a breakdown of resource usage and the generation of detailed reports. Hence, it can be seen that planning systems will play a significant role in resolving data incorporation problems.

\subsection{Tools for supporting resource efficiency}

To be resource efficient we need to be resource aware regarding what we measure and control. There are various tools to supplement resource-aware decision making, such as water, food waste, and energy KPIs (WFE KPIs), improvement tools, real-time resource consumption, decision support systems (DSSs). For instance, water, energy, and food waste smart meters provide detailed information on water and energy consumption and the amount of food waste created, which can help in structuring a new set of WFE KPIs, to improve the performance of individual machines, sub-actors and actors.

The incorporation of improvement tools can play a significant role in enhancing resource efficiency. In many cases, resource usage and food waste are currently estimated, fixed or inaccurate. For example, food waste is hard to measure since it is hard to distinguish low-

value food waste from high-value food waste when they are binned together. Traditional ways of tracking food waste such as pen and paper are not good enough as they are prone to errors and often estimated. But with the use of food waste smart meters, it is possible to identify different categories of waste, record their exact weights and establish a better highvalue solution for the waste generated. 
Real-time water and energy consumption and food waste data are essential since they enable stakeholders, operators, and other management staff to understand consumption and wastage behaviour and patterns. Incorporating resource consumption and wastage data into FSC management decisions requires a decision support system (DSS) to support decision making with regards to resource usage and wastage. The function of a DSS is to equip stakeholders to support the efficient use of resources in FSCs and to provide solutions to operational needs, such as quicker response to external events (price changes, shortages, etc.).

\subsection{Incorporation of resource data into FSC management decisions}

At the top level, the framework supports FSC management decisions such as strategic, operating and control decisions that can be made more resource efficient when incorporated with water, energy, and food waste data.

At the strategic level, decisions relating to products, processes and facilities are undertaken such as developing long-range production plans, process design, selecting and managing production technology, planning the arrangement of services and planning for the optimal distribution of scarce resources among product lines, sub-actors or actors and long-term production capacity. The improvement of resource efficiency can be achieved through techniques for efficient food processing and the redesigning of food manufacturing processes to reduce time.

The focus of operational management is on food production and meeting demand. It involves, inter alia, aggregate planning, production scheduling, planning and controlling finished goods inventories, planning materials and capacity requirements, short range decisions about what to produce and when to produce and managing all facets of the material system. Knowledge of resources required by a particular food processing machine at various settings and configurations will enable the stakeholder to understand the most effective, 
efficient and economic setting for the machine. This information, when fed into the production scheduling systems, can reduce water and energy consumption as well as reduce food wastes.

In control decisions, there is more focus on planning and managing operations such as planning for the effective and efficient usage of human resources in operations, planning and controlling the quality of products and services, projects and maintaining the machines and facilities. Techniques such as line balancing, i.e. having the right number of people for a particular task, and getting it right the first time, avoids recycling. The predictive maintenance of machines prevents unwanted breakdowns. All these techniques will ultimately lead to less consumption of water and energy and reduce food waste.

\section{Conclusions and Further Work}

In this paper, we have addressed the issue that stakeholders need to reflect upon while they are planning to improve resource efficiency in FSCs using IoT technologies. Although, the IoT has brought a high level of visibility, transparency, awareness, flexibility and the ability to collect and process a large amount of data in the real-time, but, failure to properly implement it, may result in financial disaster. Consequently, for this reason, it becomes essential to develop a strategy beforehand on how to integrate IoT resource monitoring system in the FSCs initiatives to attain environmental sustainability. It focuses on the technology needed to gather and analyse IoT data and focuses on tools that are required to support the system to achieve resource efficiency. It further illustrates an IoT-based framework and a methodology which provides a new perspective on incorporating water, energy and food waste data into FSC management and decision-making. Incorporating realtime data into supply chain planning systems such as SAP, APS (Advanced Planning 
System), MRP (Material Resource Planning), and ERP will help stakeholders with better decision-making to optimise resource consumption and reduce wastage.

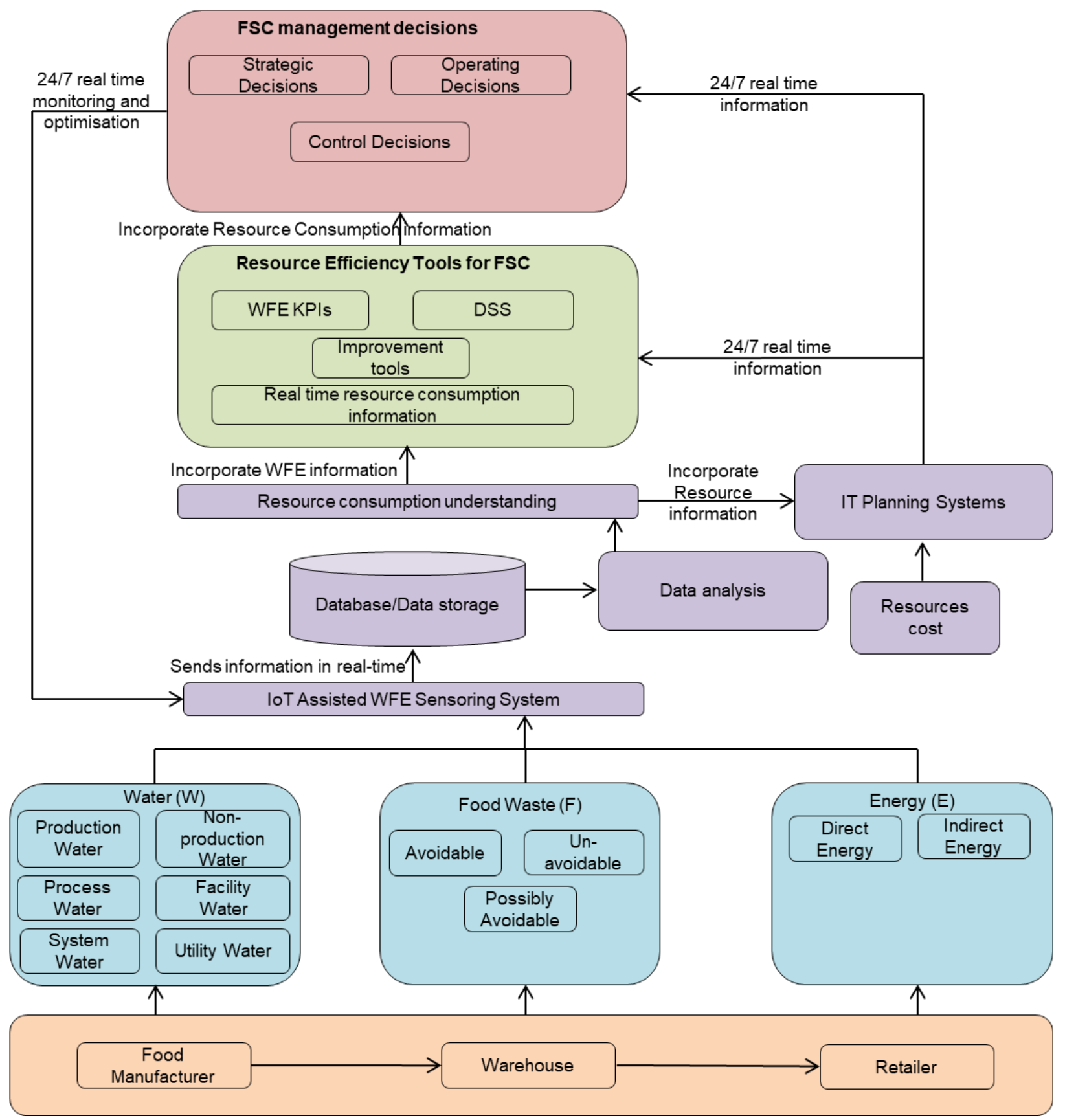

Figure 5 Methodology for IoT- based incorporation of data into FSC decisions

This paper has clearly added value that a well implemented IoT-based resource monitoring system provides detail insights into supply chain activities. And, the supply chain individuals do not have to spend enormous time gathering the essential data. It readily offers them with 
the available information needed to swiftly address resource inefficient activities within FSC, as well as determining the root cause and fixing them resulting in cost savings. It provides the chance to monitor all existing supply chain activities and the data related to three nexus components so that analysis can be carried out in the context of the whole supply chain. Detailed information leads to better decision making - decisions that result in resource efficient supply chains. More research is needed to explore and develop other IoT concepts for improving the resource efficiency of FSCs and embedding them in supply chain planning and control to support decision-making processes. However, the methodology presented in this paper will be utilised in future prototype development to address the issues outlined, and recommendations suggested in this work.

\section{Acknowledgements}

This work was supported by the Engineering and Physical Sciences Research Council (EPSRC) Centre for Innovative Manufacturing in Food [Reference: EP/K030957/1].

\section{References}

1. Akkas, M., 2016. Using wireless underground sensor networks for mine and miner safety. Wireless Networks, pp. 1-10.

2. Akyildiz, I., Su, W., Sankarasubramaniam, Y. \& Cayirci, E., 2002. A survey on sensor networks. IEEE Communications Magazine, 40(8), pp. 102-114.

3. Amendola, S. et al., 2014. RFID Technology for IoT-Based Personal Healthcare in Smart Spaces. IEEE Internet of Things Journal, 1(2), pp. 144-152.

4. Brabeck-Letmathe, P., 2016. Climate Change, resource Efficiency and Sustainability. In: A. Biswas \& C. Tortajada, eds. Water Security, Climate Change and Sustainable Development. Singapore: Springer, pp. 7-26.

5. Combaneyre, F., 2015. Understanding Data Streams in IoT, Cary: SAS. 
6. Compare Business Products, n.d. Enterpriseinnovation.net. [Online] Available at:

http://www.enterpriseinnovation.net/files/whitepapers/top_10_erp_vendors.pdf [Accessed 0501 2017].

7. DEFRA, 2002. The Strategy for Sustainable Farming and Food. Facing the Future.. [Online]

Available at:

http://www.randd.defra.gov.uk/Document.aspx?Document=DO107_9829_FRP.pdf [Accessed 27 September 2016].

8. European Commission, 2011. Sustainable food consumption and production in a resource-constrained world, Brussels: European Commission.

9. FAO, n.d. Sustainable food consumption and production. [Online]

Available at: http://www.fao.org/ag/ags/sustainable-food-consumption-andproduction/en/

[Accessed 26 September 2016].

10. Gubbi, J., Buyya, R., Marusic, S. \& Palaniswami, M., 2013. Internet of Things (IoT): A vision, architectural elements, and future directions. Future Generation Computer Systems, 29(7), pp. 1645-1660.

11. Haight, J. \& Park, H., 2015. IoT Analytics in Practice, Boston: Blue Hill Research.

12. Haller, S., Karnouskos, S. \& Schroth, C., 2008. The Internet of Things in an Enterprise Context. Berlin-Heidelberg, Springer, pp. 14-28.

13. Hancke, G., Silva, B. \& Hancke Jr., G., 2012. The Role of Advanced Sensing in Smart Cities. Sensors, 13(1), pp. 393-425. 
14. Henningsson, S., Hyde, K., Smith, A. \& Campbell, M., 2004. The value of resource efficiency in the food industry: a waste minimisation project in East Anglia, UK. Journal of Cleaner Production, 12(5), pp. 505-512.

15. Iotsens, 2017. Smart Water Metering. [Online]

Available at: http://www.iotsens.com/smart-water-metering/ [Accessed 13 March 2017].

16. Jagtap, S. \& Rahimifard, S., 2017. Utilization of Internet of Things to Improve Resource Efficiency of Food Supply Chains. Chania, Greece, CEUR-WS.org, pp. 819.

17. Jedermann, R., Nicometo, M., Uysal, I. \& Lang, W., 2014. Reducing food losses by intelligent food logistics. Philosophical Transactions of the Royal Society A: Mathematical, Physical and Engineering Sciences, 372(2017).

18. Jesus, E., Chicarino, V., de Albuquerque, C. \& Rocha, A., 2018. A Survey of How to Use Blockchain to Secure Internet of Things and the Stalker Attack. Security and Communication Networks, Volume 2018, pp. 1-27.

19. Kim, Y., Evans, R. \& Iversen, W., 2008. Remote Sensing and Control of an Irrigation System Using a Distributed Wireless Sensor Network. IEEE Transactions on Instrumentation and Measurement, 57(7), pp. 1379-1387.

20. Koh, L., 2014. Advanced Resource Efficiency Centre (AREC) - Creating the Supply Chain of the Future. [Online]

Available at: https://www.sheffield.ac.uk/polopoly_fs/1.445286!/file/ARECBrochure2015.pdf [Accessed 27 September 2016].

21. Lee, P. et al., 2013. The role of Lean thinking in increasing resource efficiency in the UK food and drink supply chain.. [Online] 
Available at:

http://www.oakdenehollins.co.uk/media/270/11668_20131114RevisedLeanresearchre port-DEFR01270FO0425_from_defra_website.pdf

[Accessed 21 September 2016].

22. Li, S. \& Xu, L., 2017. Securing the Internet of Things. Cambridge: Syngress.

23. Matopoulos, A., Barros, A. \& van der Vorst, J., 2015. Resource-efficient supply chains: a research framework, literature review and research agenda. Supply Chain Management: An International Journal, 20(2), pp. 218-236.

24. Pang, Z., Chen, Q., Han, W. \& Zheng, L., 2012. Value-centric design of the internetof-things solution for food supply chain: Value creation, sensor portfolio and information fusion. Information Systems Frontiers, 17(2), pp. 289-319.

25. Parfitt, J., Barthel, M. \& Macnaughton, S., 2010. Food waste within food supply chains: quantification and potential for change to 2050. Philosophical Transactions of the Royal Society B Biological Sciences, 365(1554), pp. 3065-3081.

26. Pitarch, J. et al., 2017. Optimisation of the resource efficiency in an industrial evaporation system. Journal of Process Control, Volume 56, pp. 1-12.

27. Rahimifard, S. et al., 2017. Forging New Frontiers in Sustainable Food Manufacturing. In: G. Campana, R. Howlett, R. Setchi \& B. Cimatt, eds. Sustainable Design and Manufacturing 2017. Bologna: Springer, pp. 13-24.

28. Ray, P., 2016. A survey on Internet of Things architectures. Journal of King Saud University - Computer and Information Sciences.

29. Sachidananda, M., 2013. A framework for modelling and reduction of water usage in the manufacturing industry. Loughborough: Loughborough University.

30. Satyavolu, P., Setlur, B., Thomas, P. \& Iyer, G., 2014. Designing for Manufacturing's 'Internet of Things', Teaneck: Cognizant. 
31. Seow, Y., 2011. A framework for modelling embodied product energy to support energy efficient manufacturing. Loughborough: Loughborough University.

32. Sethi, P. \& Sarangi, S., 2017. Internet of Things: Architectures, Protocols, and Applications. Journal of Electrical and Computer Engineering, Volume 2017, pp. 125.

33. Shahrokni, H., van der Heijde, B., Lazarevic, D. \& Brandt, N., 2014. Big Data GIS Analytics Towards Efficient Waste Management in Stockholm. Stockholm, 2nd International Conference on ICT for Sustainability.

34. Solaredge, 2016. SolarEdge Monitoring Server API. [Online] Available at: http://www.solaredge.com/sites/default/files/se_monitoring api.pdf [Accessed 27 October 2016].

35. Thollander, P. \& Ottosson, M., 2010. Energy management practices in Swedish energy-intensive industries. Journal of Cleaner Production, 18(12), pp. 1125-1133.

36. Verdouw, C., Wolfert, J., Beulens, A. \& Rialland, A., 2016. Virtualization of food supply chains with the internet of things. Journal of Food Engineering, 176(2016), pp. 128-136.

37. Villamayor-Tomas, S. et al., 2015. The Water-Energy-Food Security Nexus through the Lenses of the Value Chain and the Institutional Analysis and Development Frameworks. Water Alternatives, 8(1), pp. 735-755.

38. Wang, A. \& Zhang, Q., 2014. Application of the Internet of Things Technology in Food Safety Monitoring and Controlling System. Advanced Materials Research, Volume 1006-1007, pp. 534-537.

39. Webb, P., 2016. Modelling, Monitoring and Management of Water Consumption in Food Manufacture. Loughborough: Manufacturing Food Futures Conference . 
40. WRAP, 2009. Household Food and Drink Waste in the UK. [Online]

Available at:

http://www.wrap.org.uk/sites/files/wrap/Household_food_and_drink_waste_in_the_U

$\underline{\text { K_- report.pdf }}$

[Accessed 3 August 2017]. 